\title{
COUNSELLING IN PHYSIOTHERAPY
}

\author{
A. MATHIAS, \\ Chief Physiotherapist Johannesburg Hospital
}

Counselling is an inherent part of the practice of physiotherapy but many, if not most, physiotherapists are unaware of the power of this particular modality which they have at their disposal, or literally hold in their hands. This may be due to the fact that they have never consciously considered this part of their work, or it may be due to a fear of being thought of as encroaching on the activities of other disciplines. "There is an important dilemma which must be recognised . . . . .! those with the most contact, interest and best relationship with the counselee often have the least training in counselling techniques, and may feel anxious about getting out of their own areas of supposed expertise. Referral to a properly 'qualified' counsellor is often difficult or may be resisted." 1

However, consider the definition of counselling as "a very wide concept; the process of helping someone mobilise his own resources to cope with a problem which he had previously found insurmountable; which includes giving information." 2

In addition, take into account other aspects of counselling in which physiotherapists are frequently engaged, such as positive listening, verbalisation, advice-giving and re-assuring, as well as the establishment of a relationship with the patient. It is clear that the physiotherapist is involved in a situation where increased knowledge on her part would benefit herself and her patient, as well as her colleagues.

It has been said that "the greatest theoretical understanding of the dynamics of counselling is no substitute for a wish to help people in trouble. Equally the best natural helper can always increase his aptitude by understanding what he is doing." 3

"Who can or should do it? If one does away with arguments which aim at protecting the business and activities of a particular profession, the answer is that probably anyone with certain characteristics and interests could do some counselling which might be helpful generally."

Roger Freeman, of the Department of Psychiatry, University of British Columbia, Vancouver, Canada, in listing the characteristics, mentioned in his question above, emphasises that "the wish to help is not enough". He lists the "ability to listen, without jumping in with advice and interpretations or moralising .... and associated with this, a belief that listening is useful in itself". $\mathrm{He}$ also states that "the counsellor should not need the counselee to be grateful, or to change, but to have his or her sources of satisfaction and selfworth. This implies reasonable intelligence and maturity". ${ }^{4}$

The physiotherapist engaged in counselling needs increased knowledge to protect her patient and herself from difficulties which arise in these situations, one of which, emotional overinvolvement, being used frequently in accusations against them. Essentially, the physiotherapist should know her own limitations and be able to recognise the need of her patient for referral to other workers for help, when necessary. This recognition or awareness on the part of the therapist of the patient's depth of disturbance being beyond her own capabilities, is obviously a crucial point. Whether or not there is a qualified counsellor available to help the patient, the physiotherapist should try to make sure that she always has access to such a person for help, and she should consult this mentor whenever any doubt arises. In such discussions the physiotherapist will also gain insight inte her own feelings and problems, "and if we are reall to be useful to our patient, we have to learn to deal with our own anxieties". For instance, we must be able to understand and deal healthily with our own reactions to change and new experiences, to contact with tragedy, death, severe mental disorder, operations which have deep emotional significance, e.g. hysterectomy, abortion, breast amputation, or with serious illness in children. ${ }^{5}$

It is in advice-giving and reassurance that the physiotherapist is often engaged. Both these activities are in general regarded as "the hallmark of the unskilled in social work". However, the physiotherapist does not give advice as much as information and instruction, which is her responsibility to the patient and his family. In offering reassurance the therapist should not do so to allay her own anxiety and helplessness, but do so only on those subjects on which she is expert or knowledgeable.

As regards the relationship between the therapist and the patient, this is influenced by many factors.

Firstly, by the undcrstanding on the part of physiotherapist of the behaviour of the patient, as influenced by his illness. She should know that "quite apart from the actual symptoms and discomforts of physical illness being sick has very profound psychological effects" Writing in "Human Behaviour in Illness", Lynn Gilli: also remarks that "There is more to recovery than the physical processes going on in the body and peopl normally do have a fund of recuperative power that wil provide a force for living if only it can be tapped. Al who have to do with sick people must learn to work with this recuperative power and by support, guidance and encouragement, assist the patient to find the will $t c$ get better. The cardinal rule for achieving this is to combat dependence.

He continues to say that we all accept that a patien has to be physically rehabilitated after illness, "but it is not often realised that even in physical illness, there is a process of mental convalescence to be gone through".?

Obviously, the physiotherapist needs to take part in counselling, knowing the above, as she does with parents of handicapped children, being aware of their attitudes to their handicapped child. ${ }^{8}$

Another factor influencing the relationship between the physiotherapist and her patient is the understanding on the part of the therapist, that "the patient, whatever his stated need for help, approaches the therapist with various emotional attitudes that may facilitate or complicate his co-operation in treatment. Equally, the therapist should have insight into the most important motivations in doing what he (or she) is doing, and be aware of the ways in which he is approaching his work and 
is patients'. When the patient and the therapist meet he results will depend on the combination of the the rapist's learnt skills and the emotional interaction between them."

We need to increase our knowledge of these areas of interpersonal relationships not only to improve the treatmotivation of our patients but also to work ment andidisciplinary team in the most productive way, in a multidor our personal benefit, for, "a good human as weinship may in itself be regarded as phychotherarelationship 10

peutic". recognised that physiotherapists are in "a key

It is recognition" 11 as regards counselling, as are therapeutic position and some other lay workers. The doctors, clergymeir treatment, as well as the frequently frequency of such treatment, contributes greatly to long

this.

In addition they use, as an integral part of their work, most immediate method of establishing contact with the person, viz. touch. The importance of this anot of their treatment needs emphasis.

aspect of therms of Desmond Morris, "the act of intimacy In whenever two individuals come into bodily concomething special happens when two people touch tact. another physically-bodily contact is the most basic form of communication." 12

In answering a query about the benefits of passive movement, Charles Kennedy, MB, Associate Professor of Paediatrics in Neurology, University of Pennsylvania, commented as follows:

"Finally, and most particularly, it should be noted that passive movement, independent of the pattern in which it is carried out, is but one form of a laying on of hands. Throughout the history of mankind one finds some aspect of this as an integral part of practices in the art of healing, and however deficient our knowledge may be in the neurophysiology of higher psychic processes, there can be no denial of the important role of the authoritative and by definition, optimistic therapist, whose presence is felt in the very literal sense." 13

This aspect is present not only in passive movement, but in the most active and strenuous of rehabilitation programmes-to quote Miss S. H. McLaren, M.C.S.P., Superintendent Physiotherapist, Durham Miners' Rehabilitation Centre:

"Always use names-the only personal part of a ratient; otherwise he is just a computerised number on filing card. Always use contact, patient to patient, herapist to patient. So much conveyor-belt, machanised, mputerised work goes on that he has often lost the bility to touch and feel touched." 14

Our disposition toward the patient is reflected in the way in which we touch to massage, to assist, or resist, or simply to lay a comforting hand; and greatly affects our relationship with the patient and the outcome of our treatment to him. This is especially so in the treatment of infants, because "it is not words so much as acts communicating affection and involvement that children, and, indeed, adults, require". ${ }^{15}$ This author suggests "that adequate tactile satisfaction during infancy and childhood is of fundamental importance for the subsequent healthy behavioural development of the individual".

Nevertheless, in reviewing the literature, there has been very little clinical analysis of the counselling aspect of physiothrapy.

In "The Physical Therapist as Parent Counsellor, an Emerging Role", George J. Goldin, MD, reports on a study made of the physical therapist's role in meeting the psycho-social needs of the physically handicapped child and its parents. ${ }^{16}$
The findings established that physical therapists are, in fact, much engaged in counselling the parents of handicapped children and that they view such counselling as a legitimate part of their role. In view of these findings the following questions were posed:

"What are the boundaries of the physical therapist's role? How does the parent counselling of the physical therapist differ from that carried out by the medical social worker and what are the areas of counsellor role overlap?

"How does the physical therapist best train for his parent counselling role? For new physical therapists how is it introduced and handled in the curriculum? For practising physical therapists, how is counselling skill best developed on the job?"

These questions are as pertinent to us as the actual involvement of the physiotherapist in counselling is real.

This involvement is augmented by the fact that in most centres for the treatment of handicapped children it is the physiotherapist who is primarily and continually engaged in the treatment of the child and the instruction of the parents. ${ }^{17}$ This contact even outweighs, but should not replace, the presence and attention of an interested social worker, and should certainly not interfere with the latter, but indeed complement the work of the social worker. In order that we may satisfactorily increase our contribution towards our patients' welfare, we should find the answers to the questions asked above, and implement them with action.

\section{REFERENCES}

1, 4 FREEMAN, ROGER D. "Counselling Techniques" Instructional Course, American Academy for Cerebral Palsy, 29th Annual Meeting, New Orleans, 1975.

2, 3, BESSEL, ROBERT. 1971. "Interviewing and Coun6, 11 selling", B. T. Batsford Ltd., London.

5, 7 GILLES, LYNN. 1972. "Human Behaviour in Illness; Psychology an Interpersonal Relationships". Faber Editions.

8 MacKEITH, R. 1973. "The feelings and behaviour of parents of handicapped children". Developmental Medicine and Child Neurology, August 1973, Vol. 15, pp. 524-27.

9 BLAKE, Y. "Patient-Therapist Relationship". Paper read at Jubilee Congress, South African Society of Physiotherapy, Johannesburg 1975.

10 MASLOW, A. H. "Motivation and Personality". Harper and Row Publishers, New York, London.

13 KENNEDY, CHARLES. Physical Therapy. March 1968, Vol. 48, No. 3, page 257.

14 McLAREN, S. H. "Play for Work". South African Journal of Physiotherapy, December 1975, Vol. 31, No. 4, pages 9-11.

15 MONTAGUE, ASHLEY. "Touching: The Human Significance of the Skin". Columbia University Press. New York, London, 1971.

16 GOLDIN, G. J. "The Physical Therapist as Parent Counsellor-an Emerging Role". Physical Therapy, July 1965, Vol. 45, No. 7, pages 677-682.

it GORDON, NEILL. "Parent Counselling". Developmental Medicine and Child Neurology, October 1972, Vol. 14, No. 5, pages 657-659. 